\title{
Biodiversity of the Micro-morphologies of the Petal Epidermis of Angiosperms \& Their Scientific Aesthetics, Quasi-Geometry
}

\author{
Shaoyong Yang1, Dixin $\mathrm{Wu}^{2}$, Hua Wang33, Weibo Liư ${ }^{4}$, Dongming Zhou ${ }^{5}$, Fan $\mathrm{Du}^{6 *}$ \\ ${ }^{1}$ School of Landscape \& Horticulture, Southwest Forestry University, Kunming, China \\ ${ }^{2}$ School of Landscape Architecture, Beijing Forestry University, Beijing, China \\ ${ }^{3}$ Department of Economic Plants \& Biotechnology, Kunming Institute of Botany, Chinese Academy of Sciences, \\ Kunming, China \\ ${ }^{4}$ School of Mathmatics \& Statistics, Yunnan University, Kunming, China \\ ${ }^{5}$ The Environment \& Health Research Center, Eco-Development Academy, Southwest Forestry University, Kunming, China \\ ${ }^{6}$ School of Forestry, Southwest Forestry University, Kunming, China \\ Email: 1838384305@qq.com, chineseflowers@163.com,huhong@mail.kib.ac.cn,wbliu@ynu.edu.cn, \\ dongming.zhou@qq.com, *kmdufan@163.com
}

How to cite this paper: Yang, S.Y., Wu, D.X., Wang, H., Liu, W.B., Zhou, D.M. and Du, F. (2021) Biodiversity of the Micro-morphologies of the Petal Epidermis of Angiosperms \& Their Scientific Aesthetics, Quasi-Geometry. American Journal of Plant Sciences, 12, 1051-1058.

https://doi.org/10.4236/ajps.2021.127073

Received: June 3, 2021

Accepted: July 19, 2021

Published: July 22, 2021

Copyright $\odot 2021$ by author(s) and Scientific Research Publishing Inc. This work is licensed under the Creative Commons Attribution International License (CC BY 4.0).

http://creativecommons.org/licenses/by/4.0/

\section{(c) (i) Open Access}

\begin{abstract}
The micro-morphologies and biodiversities of the epidermis of flower petals of angiosperms were reported for the first time. By manual slicing anatomy and microscopic photography technique, the micro-morphologies of the upper and lower epidermis of petals of some common ornamental flowers in Kunming were studied, and the biodiversities were discovered. The results showed these much-varied pigment cells appeared not only a new compensation to anatomy, but a new criteria to taxonomy, so that a brand new research field of "Cell Taxonomy" was established instead of the current "Chromosome Taxonomy" widely used in phytosystematics research. Furthermore, the most interesting and significant phenomena was their scientific aesthetics: these pigment cells of flower petals were quite special, planary, far different from the ordinary plant cells in plant organs \& tissues. By comparison to ordinary geometry, these colorful cells of the fresh flower petals could be described as "Quasi-geometry" for their special origin and micro-morphological characteristics. As for the aspect of art, it was quite similar to "Quasi-crystal" discovered by Daniel Schechtman, so that the art future was discussed, obviously another new epoch of scientific-art history began.
\end{abstract}

\section{Keywords}

Biodiversity, Micro-Morphology, Petal Epidermis, Pigment Cells, Scientific

${ }^{\star}$ Corresponding author. 
Aesthetics, Quasi-Geometry, Planarity, Scientific Popularization

\section{Introduction}

There are many kinds of cells in different plant organs \& tissues [1] [2], and each kind of cells have their specific functions, such as the epidermal cells of leaves, their main function is photosynthesis, now many researches have been done for their systematics [3]. As for the micro-morphologies of the epidermal cells of flower petals, there had been no development since Japanese scientists' histo-chemistry researches about the pigment cells [4]-[18]. However, our researches lasted 30 years since 1990, and provided a new compensation to anatomy. Tens species (or cv.) were studied and many new micro-morphologies \& biodiversities were discovered, such that a new taxonomical criteria was set up because we used the full grown matured flowers. And at last, many scientific aesthetics have been discovered, it is a breakthrough in art history beside Fractal and Quasi-crystal shown in Figure 1 \& Figure 2.

\section{Materials and Methods}

The petals were collected randomly in Kunming Botanical Garden, Kunming Institute of Botany, CAS, during Oct. 2005-March 2008, sporadically, mainly

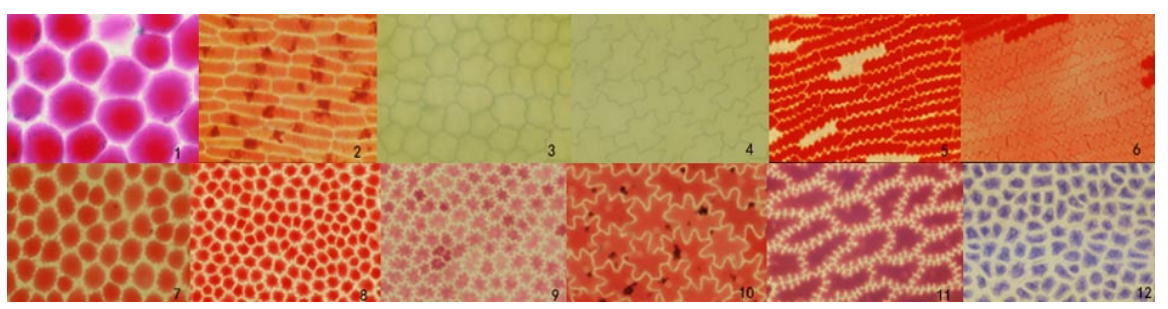

Figure 1. Biodiversity and scientifc aesthetics of the micro-morphology of the epidermis of flower petals. 1) Dalia pinnata Cav. (purple), upper epidermis; 2) Gerbera jamesonii Bolus (orange), lower epidermis; 3) Chrysanthemum multicaule (yellow), upper epidermis; 4) Chrysanthemum multicaule (yellow), lower epidermis; 5) Papaver rhoeas L. (red), upper epidermis; 6) Papaverhoea L., lower epidermis; 7) Pelargonium horturum Bailey (red), lower epidermis; 8) Verbena hybrid Voss. (red), upper epidermis; 9) Verbena hybrid Voss. (violet), lower epidermis; 10) Clematisflorida Thunb. (purple), lower epidermis; 11) Viola tricolor L. (velvet deep purple), lower epidermis; 12) Delphinium grandiflorum (blue), lowerepidermis.

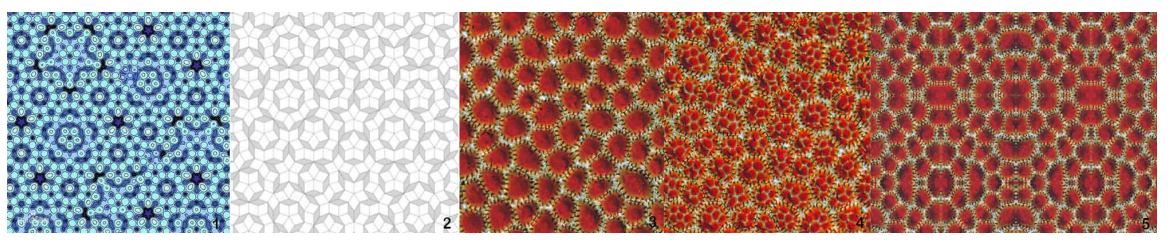

Figure 2. The comparison between quasi-crystal and quasi-geometry. 1) Quasi-crystal; 2) Quasi-crystal; 3) The micro-morphology of the petal lower epidermis of Cunnaindica L; 4) One quasi-geometry form; 5) Another quasi-geometry form. 
between Nov. 2005 Nov. 2006, one year round. Figure 1 shows the results of 9 species (var. or cv.) of Dalia pinnata Cav. (purple), Gerbera jamesonii Bolus(orange), Chrysanthemum multicaule (yellow), Papaver rhoeas L. (red), Pelargonium horturum Bailey (red), Verbena hybrid Voss. (red), Verbena hybrid Voss. (violet), Clematis florida Thunb. (purple), Viola tricolor L. (velvet deep purple) and Delphinium grandiflorum (blue), belonging to 9 genus of Dalia, Gerbera, Tagetes, Papaver, Pelargonium, Verbena, Clematis, Viola and Delphinium and 6 families of Compositae, Papaveraceae, Geraniaceae, Verbenaceae, violaceae and Ranunculaceae.

\section{Results \& Discussion}

\subsection{There Is a Difference between the Micro-Morphology of the Upper and Lower Epidermal Cells}

Figure 1 shows Chrysanthemum multicaule (yellow), Papaver rhoea L., Verbena hybrid Voss. (red) and Verbena hybrid Voss. (violet), the former and later are much different, but the middle slight different. Mostly, the lower epidermal has a much compact structure and the cell patterns are more clear, diversified, complicated and beautiful.

\subsection{The Size Differences between the Upper and Lower Epidermal Cells}

Mostly, the upper cells have smaller sizes because the pigments are accumulating on the upper epidermis while the lower epidermis has only a tight layer, so that the lower epidermis cells are mostly bigger, but the situation is on the contrary such as the flowers of Salvia spendens Ker-Gawler, the outer layer has a more compacted structure such that the cells are bigger and the inner layer has more tip hairy cells.

\subsection{Pigment Components Affect the Cell Morphology}

Carotonoids mostly appear as granules, see Figure 1 Gerbera jamesoni Bolus.

Anthocyanins appear most diversified both morphologically and colors. See Figure 1. Dalia pinnata Cav., Papaver rhoe L., Pelargonium horturum Bailey, Verbena hybrid Voss., Clematis florida Thunb, Viola tricolor L., and Delphinium grandiflorum.

\subsection{Water Content of the Petals Affects the Cell Morphology}

According to our research of some genus \& species of Compositae (unpublished), it seems with the decrease of water content of petals, the morphologies of the pigment cell change from spherical, wavy spherical, regular multi-angular, regular oval to long oval, rectangular, oblong to stripes, such as the natural dry flower Helichrysum bracteatum, the pigment cells are all stripes.

\subsection{Morphologies, Diversities \& Micro-Morphological Taxonomy}

The specific characteristics and patterns of the research results can be as a tax- 
onomical criteria, such as genus Viola, the cell morphology of the petal epidermal is always the same, shown by Figure 3, so that there is no doubt that a new criteria can be established because we use full-grown petals, or just withered, not the growing stage ones, if the herbarium specimens could be used, we possibly could get the right result without the fresh colors. According to the above results shown by Figure 1, it is a necessity to establish a set of terminologies to describe these much diversified micro-morphologies. "Quasi-geometry" is just a general designation, such that a new research field with a new taxonomical criteria can be set up so that further research can be carried on systematically. Following are some terms of the micro-morphologies:

- Stripes. Most yellow flowers of Compositae, such as Calendula Officinalis, their epidermis cells are always stripes.

- Circular, ellipse, pentagonal, hexagonal etc., most red flowers containing anthocyanins such as Camellia, Rose, Dalia etc. have these morphologies.

- Rectangle, linear, narrow rectangular, such as Gebera jamesoni Bolus.

- Wavy pentangle, such as Clematis, Athrae etc.

- Dentle torpedo: Viola tricolor Cav. Shown in Figure 3.

- Wavy square-spherical, wavy spherical, multi-wavy flower shape, broad wavy flower shape, broad irregular wavy multi-angular, flower-like shapes or bio-holographics (Yingqing Zhang, 1985), Jasminum, Forthysia, Chrysanthemum multicaule, Verbena, Clematis etc.

- Multi-angular: Vinca major.

- Wavy nodes or wavy linear: Papaver rhoeas $\mathrm{L}$.

- Irregular geometry of triangle, rectangle to spheres, irregular clypeiform such as Delphinium.

- Dentle rectangle, Penstemon campanulatus.

- Wavy triangle: Tropaeolum.

- Micro-wavy spherical: Such as Pelargonium horturum.

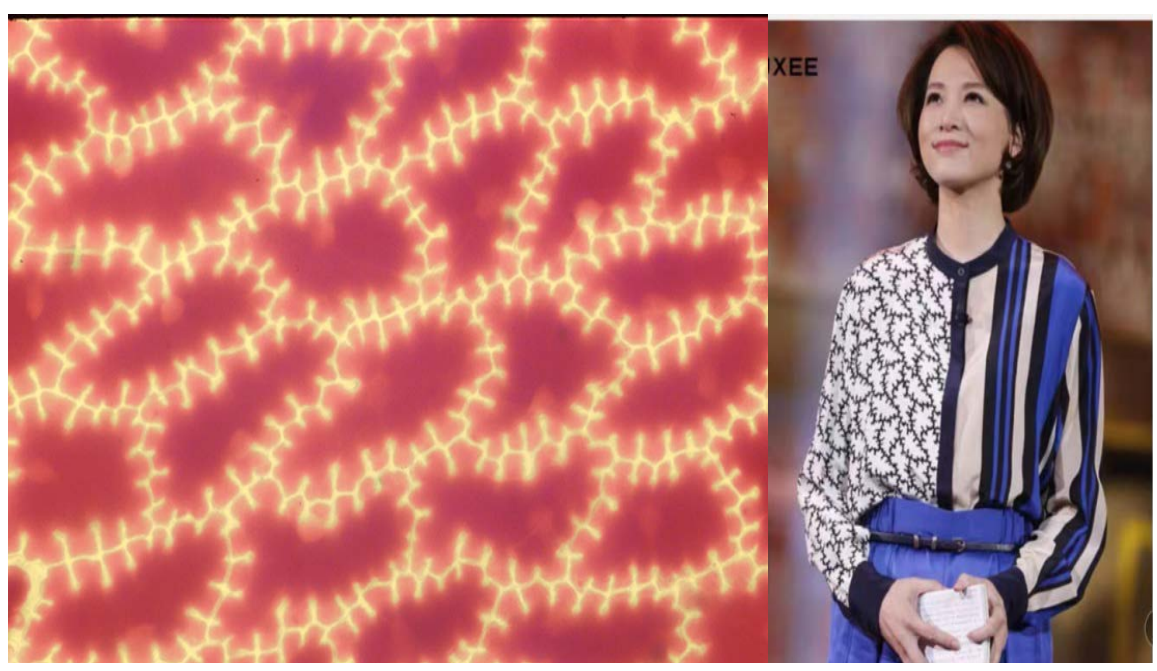

Figure 3. Scientific aesthetics, quasi-geometry, from the micro-morphology of the lower epidermis of Viola tricolor (velvet deep purple ) \& a related fashion, the Dong Qing Style. 


\section{Conclusion}

\subsection{Biodiversity}

There are many kinds of micro-morphological biodiversities in the upper and lower epidermal pigment cells of the flower petals of Angiosperms, mainly entomophilous \& ornithophilous pollenation groups. These micro-morphologies are much varied, for their special functions basing on their planarity and beautiful patterns, hereafter a new term of mathematics, "Quasi-geometry" is thus introduced to describe these closed, with natural fractal wavy curved lines spheres, which are far different from the micro-morphologies of pollens [19], some of them are similar to that of leaves, however, they are much diversified and artificial than that of leaves. Chinese has a proverb of: "art cell" - if someone is said having no art cell, it means he is not good at art. No wonder, cell is surely art, or at least a potential artist. Chinese has another proverb of: "One flower, one world!" Actually, not only one flower is a world, but one cell is a big world, so that the most interesting result of our research is the specific function of the petal epidermis cells, the "art cell", this is a very secret covered in nature during such long human history of thousands years.

\subsection{Anatomy}

It is a very important compensation to anatomy, and a new beautiful field. We all know the diversity of plant cells, however, we have not carried any research about the pigment cells of flower petals, or the drapery of flowers! Now we have discovered more and more micro-morphologies, or planary art patterns designed by nature-a psalm says: "the wild flowers wear beautiful clothes, and the birds never worry about their foods", epidermal cells have their specific characteristics of planarity, so that they should be the best art designs for our clothes. Nature provides everything for humans including the most beautiful clothes, the research could provide innumerable art creation resources, we open a new epoch of art.

\subsection{Scientific Aesthetics}

Figure 1 shows a lot of beautiful natural aesthetics-which have never been discovered before because the microscopic was created by Leeven Hook about 300 years. Possibly the most significant discovery of this research is just the scientific aesthetics. In the art history, these kinds of new art patterns from the micro-botany have never been discovered and used practically on fabircs. Now we successfully used them in the fabrics designs or other covering materials, we got not only many prizes with astonished remarks by the people. Following are some examples:

1) Award 2007 FCC (Fabrics China Creation), the award ratio is 60 among tens thousands;

2) Excellent Prize by the First Pattern Design Competition of Silks, the Fam- 
ous Tie City of China, the award ratio is $39 / 888$;

3) The Best Suggestion Award by the First International Pattern Design Competition of Fabrics, Hongkong Beiqi Cloth Art, the award ratio: 21/985, a special award;

4) Two Prize Certificate of the Accessit of Creative Design 2012 of China Package;

5) Award of Excellence, The sixth National Design Art Grand Prix, Creative China, for package;

6) Three Prize of Award, The sixth National Design Art Grand Prix, Creative China, for wall paper;

7) Award of Diexun \& Gaiqi Fashion Design Competition;

8) Honorary Science Communication Contributor, 2018 China International Contest of Science Popularization;

9) Award of The $5^{\text {th }}$ China Silk Hometextiles Creation Cometition, 2021.

We used the above research results for art designs and then had exhibited on http://www.fswchina.com/ during the whole year of 2008: the textiles colleagues immediately recommendated them to the biggest capacity fluent picture web in the world for their amazing beautiful art effect, following are some high remarks: "These kind of designs are so new and entertaining!"; "Designs are so beautiful, new and elegant, fashionable and noble, surely be the future trend!"; "The designer is so creative and the designs feels so good!" and: "Designs are elegant and soothing, quite attractive!", another comment said: "When I saw your design, I suddenly lost my sense-I am not seeing a cloth design, but an artistic masterpiece". No wonder, Jesus says in "Bible": "Even the richest King Solomon of Isreal, what he wore is not as magnificent as a lily flower in the wild!" Flowers are really wearing their beautiful clothes which had not been known by people for thousands years.

These patterns can be used as art pattern design for fabrics, construction materials, decorations, wall papers, covering materials, packages and artifacts such as porcelines. And we found that no matter what kind of morphologies they appear, they not only take beautiful colors \& morphologies with nature balanced proportions with a natural harmonious beauties, so that we describe these much diversified epidermal cells of flower petals as "Quasi-geometry" by compared to ordinary geometries and "Quasi-crystal" shown by Figure 2 \& Figure 3. This is a great significance searched long history by the greatest scientists such as Madame Curi and Zhengdao Li etc. People longed for a beautiful world which could heal not only their physiological problems but psychological problems in the polluted and pressing world, "Scientific Aesthetics Therapy" could heal our soul wounds-if the noted physicist Shousheng Zhang had known what really means: "one flower, one world" he had believed in most of life, he might not have committed suicide.

With the development of fashion trend of new designs, people need to consider not only the ecological \& environmental conditions, but limited natural 
resources! A natural \& social love to a sustainable development principle should be advocated, just like horticulture therapy, "Scientific Aesthetics Therapy" should be used to entertain our daily life so that our mental problems could be healed too such as the sorrow from the fire catastrophe of Notre Dame de Paris and the damage of Yuan Ming Yuan Park. Scientific education \& popularization could realize this aim while scientists themselves should not be blocked by their limited knowledge.

\subsection{Mathmatics and Art: Quasi-Geometry}

Mathmatics seems so abstract, the numbers boredom, without fantastic things in it, but art is on the contrary! Art has no limit and it seems only the so-called distracting mind can create it, however, the fact is: mathematics is most close to art, either "Golden Yellow Mean" and "Fibonacci Sequence" occurred often in leaves, flowers and seeds, the ratio is also accordant with the micro-morphologies, just as the Holographic Biology wrote by the potential Nobel Laureate Yingqing Zhang [20] [21], the morphology is holographical too. As for the quasi-geometry, they appear in the flower petals, with the following characteristics:

1) Biodiversity;

2) Planarity;

3) Original colors of flowers;

4) Pure scientific aesthetics;

5) Artificial varieties.

By comparison with the fractal of the ordinary morphologies of mountains, rivers, roads ect., quasi-geometry occurs in the epidermal of flowers, and appears closed curves, so that the special mathematics terminology is put forward.

\section{Conflicts of Interest}

The authors declare no conflicts of interest regarding the publication of this paper.

\section{References}

[1] Xu, X.Y., Zhang, F.J. and Guo, X.M. (2015) Botany. China Agricultural Science \& Technology Press, Beijing, 9.

[2] Xu, Y.F. and Qu, B. (2012) Botany. China Higher Education Press, Beijing, 15.

[3] Sa, R., Sudebilige, Chen, J.R. (2000) Epidermal Characters of Leaves in Thermopsis and Their Biological Significances. Acta Agrestia Sinica, 8, 65-67.

[4] Yasuda, H. and Yoneda, A. (1985) Studies on "Blueing Effect" in the Petals of Red Rose VII. Cytological Observation on the Epidermal Cells of Bluing Petals Incorporated into the Miscellaneous-Type. Journal of the Faculty of Science, 20, 15-20.

[5] Yasuda, H. (1970) Studies on "Blueing Effect" in the Petals of Red Rose, I. Some Cytochemical Observations on Epidermal Cells Having a Bluish Tinge. The Botanical Magazine, 83, 233-236. https://doi.org/10.15281/jplantres1887.83.233

[6] Yasuda, H. (1973) Studies on "Blueing Effect" in the Petals of Red Rose III. The Histochemical Detection of Iron in the Bluing Petals of Rose. Journal of the Faculty 
of Science, 8, 91-93.

[7] Yasuda, H. (1974) Studies on "Blueing Effect" in the Petals of Red Rose II. Observation on the Development of the Tannin Body in the Upper Epidermal Cells of Bluing Petals. Cytologia, 39, 107-112. https://doi.org/10.1508/cytologia.39.107

[8] Yasuda, H. (1974) Studies on the Insoluble States of Anthocyanin in Rose Petals, I. The Insoluble State of Anthocyanin and Its Relationship to Petal Color, Together with a New Instance of this Relationship. Journal of the Faculty of Science, 9, 63-69.

[9] Yasuda, H. (1976) Studies on "Blueing Effect" in the Petals of Red Rose, IV. Calcium in the Blue Spherical Body. Journal of the Faculty of Science, 11, 41-46.

[10] Yasuda, H. (1976) Studies on the Insoluble States of Anthocyanin in Rose Petals II. Histochemical Observation on Its Basal Substance. Cytologia, 41, 487-492. https://doi.org/10.1508/cytologia.41.487

[11] Yasuda, H. (1978) Studies on "Blueing Effect" in the Petals of Red Rose, V. A Survey of the Various Bluing Types. Journal of the Faculty of Science, 13, 79-86.

[12] Yasuda, H. (1979) Studies on the Insoluble State of Anthocyanin in Rose Petals III. The Obseravtion on the Developmental Process of the Massive Structure. Cytologia, 44, 687-692. https://doi.org/10.1508/cytologia.44.687

[13] Yasuda, H. (1982) Studies on "Blueing Effect" in the Petals of Red Rose VI. Further Observations on the Development of Blue Color of the Spherule. Cytologia, 47, 717-723. https://doi.org/10.1508/cytologia.47.717

[14] Yasuda, H. (1985) The Studies on the Spherical Bodies Containing Anthocyanins in Plant Cells I. Cytological and Cytochemical Observations on the Bodies Appearing in the Seedling Hypocotyls of Raddish Plants. Cytologia, 50, 397-403. https://doi.org/10.1508/cytologia.50.397

[15] Yasuda, H., Mitsui, T. and Onishi, M. (1989) Studies on the Spherical Bodies Containing Anthocyanins in Plant, Cells III. Observations on the Developments of Anthocyanoplasts in the Raddish Hypocotyls. Cytologia, 54, 673-678. https://doi.org/10.1508/cytologia.54.673

[16] Yasuda, H. (1989) The Physilogy \& Biochemsitry of Flower Colors. Translated by Fu Yulan, China Forestry Press, Beijing.

[17] Yasuda, H. (1989) The Secret of Flower Colors. Translated by Zhang Chengzhi, China Forestry Press, Beijing.

[18] Yasuda, H. and Tsujino, Y. (1988) The Studies on the Spherical Bodies Containing Anthocyanins in Plant Cells II. The Effects of Light on the Pigmentation of Spherical Bodies in the Seedling Hypocotyls of Raddish Plant. Journal of the Faculty of Science, Shinshu University, 23, 1-6.

[19] Wei, Z.X. (2003) Pollen Flora of Seed Plants. Yunnan Science \& technology Press, Kunming.

[20] Zhang, Y.Q. (1985) Holographic Biology. China Higher Press, Beijing.

[21] Zhang, Y.Q. (1985) Holographic Biology Research. Shandong University Press, Jinan. 